\title{
Der ,Vertrag der Parlamente' als Gefahr für die Demokratie? Zu den offensichtlich unbegründeten Verfassungsklagen gegen den Vertrag von Lissabon
}

\author{
Elmar Brok und Martin Selmayr*
}

515 Ja-Stimmen, 58 Nein-Stimmen und 1 Enthaltung. Mit dieser überwältigenden Mehrheit stimmte der Deutsche Bundestag am 24. April 2008 für das Zustimmungsgesetz zum Vertrag von Lissabon ${ }^{1}$ und überschritt so deutlich die für solche Verfassungsänderungen gemäß Art. 23 Abs. 1 Satz 3 in Verbindung mit Art. 79 Abs. 2 Grundgesetz (GG) vorgeschriebene Zweidrittelmehrheit. Am 23. Mai 2008 erteilte auch der Bundesrat dem Vertrag von Lissabon mit den Stimmen aller Bundesratsmitglieder (bei Stimmenthaltung Berlins) seine Zustimmung. ${ }^{2}$

Damit schien an sich der Weg frei zu sein für die wichtigste Reform der Europäischen Union seit dem Vertrag von Maastricht von 1992. Hatten sich die damals zwölf Mitgliedstaaten noch auf die Schaffung einer Wirtschafts- und Währungsunion konzentriert, soll der Vertrag von Lissabon ${ }^{3}$ jetzt vor allem eine Stärkung der Politischen Union Europas bewirken.

\footnotetext{
Elmar Brok, MdEP, außenpolitischer Koordinator der Europäischen Volkspartei; Vorsitzender des Bundesfachausschusses der CDU für Außen-, Sicherheits- und Europapolitik; Vertreter des Europäischen Parlaments auf den Regierungskonferenzen von Amsterdam und Nizza sowie jenen von 2003/2004 und 2007, die zur Annahme des Vertrags von Lissabon führten; im Verfassungskonvent Vorsitzender der Fraktion der Europäischen Volkspartei.

Dr. Martin Selmayr, Direktor des Centrums für Europarecht an der Universität Passau (CEP); im Verfassungskonvent wissenschaftlicher Berater der Europäischen Volkspartei; heute Sprecher der Europäischen Kommission, zuständig für Telekommunikations- und Medienpolitik. Der Beitrag gibt ausschließlich seine persönliche Auffassung wieder.
}

1 Vgl. Gesetzentwurf der Bundesregierung zum Vertrag von Lissabon vom 13. Dezember 2007, in: Bundestagsdrucksache 16/8300 vom 28.02.2008; Bundestagsplenarprotokoll 16/157 vom 24.04.2008, S. 16482 (D). Der Bundestag verabschiedete zuvor das Gesetz zur Änderung des Grundgesetzes (Art. 23, 45 und 93) mit 520 JaStimmen bei acht Nein-Stimmen und 49 Enthaltungen. Vgl. Gesetzentwurf der Fraktionen CDU/CSU, SPD, FDP und Bündnis 90/Die Grünen. Entwurf eines Gesetzes zur Änderung des Grundgesetzes (Artikel 23, 45 und 93), in: Bundestagsdrucksache 16/8488 vom 11.03.2008; Bundestagsplenarprotokoll 16/157 vom 24.04.2008, S. 16476 (D). Mit den Stimmen von SPD, Bündnis 90/Die Grünen, CDU/CSU, FDP bei Enthaltung der Fraktion Die Linke ist zuvor ferner das Gesetz über die Ausweitung und Stärkung der Rechte des Bundestages und des Bundesrates in Angelegenheiten der Europäischen Union verabschiedet worden. Vgl. Gesetzentwurf der Fraktionen CDU/CSU, SPD und Bündnis 90/Die Grünen. Entwurf eines Gesetzes über die Ausweitung und Stärkung der Rechte des Bundestages und des Bundesrates in Angelegenheiten der Europäischen Union, in: Bundestagsdrucksache 16/8489 vom 11.03.2008; Bundestagsplenarprotokoll 16/157 vom 24.04.2008, S. 16482 (C).

2 Vgl. Bundesratsplenarprotokoll 844 vom 23.05.2008, S. 136 (A-D).

3 Vertrag von Lissabon vom 13. Dezember 2007 zur Änderung des Vertrags über die Europäische Union und des Vertrags zur Gründung der Europäischen Gemeinschaft, in: Amtsblatt der Europäischen Union, Nr. C 306 vom 17. Dezember 2007. Eine konsolidierte Fassung des durch den Lissabon-Vertrag geänderten Vertrags über die Europäische Union (im Folgenden abgekürzt als EUV) und des geänderten sowie in „Vertrag über die Arbeitsweise der Europäischen Union“ (im Folgenden abgekürzt als AEUV) umbenannten EG-Vertrags ist veröffentlicht in: Amtsblatt der Europäischen Union, Nr. C 115 vom 9. Mai 2008. Die Nummerierung der Artikel bezieht sich auf diese konsolidierten Fassungen. Bezüge zu der derzeit geltenden Fassung des Vertrags über die Europäische Union und des Vertrags zur Gründung der Europäischen Gemeinschaften sind mit, EUVNizza' bzw. ,EGV' gekennzeichnet. Zum neuen Vertrag selbst siehe Thomas Oppermann: Die Europäische Union von Lissabon, in: Deutsches Verwaltungsblatt 08/2008, S. 473-482; Martin Selmayr: Der Vertrag ohne Pathos, in: Ernst-Joachim Mestmäcker/Wernhard Möschel/Martin Nettesheim (Hrsg.): Verfassung und Politik in der europäischen Integration, Baden-Baden im Erscheinen; Peter-Christian Müller-Graff: Der Vertrag von Lissabon auf der Systemspur des Europäischen Rechts, in: integration 2/2008, S. 123-144. 
Mit der Reform von Lissabon erfüllen sich dabei langjährige Forderungen deutscher Europapolitik, wie sie zwar bereits bei den Verhandlungen über die Verträge von Amsterdam (1997) und Nizza (2000) immer wieder erhoben, aber nur höchst unzureichend umgesetzt wurden. Mehr Rechte für das Europäische Parlament, eine kleinere Kommission, demokratischere Abstimmungsregeln im EU-Ministerrat, eine für die Union verbindliche GrundrechteCharta - all dies findet sich nun im Lissabon-Vertrag rechtlich verankert. Zu verdanken ist dies vor allem der Leistung der deutschen EU-Ratspräsidentschaft im ersten Halbjahr 2007. Bundeskanzlerin Angela Merkel gelang es, den Inhalt des Verfassungsvertrags von 2004, ${ }^{4}$ der von 18 Mitgliedstaaten gebilligt, in Referenden in Frankreich und den Niederlanden aber abgelehnt worden war, in einen neuen, um Verfassungsrhetorik und -symbolik erleichterten Reformvertrag , hinüberzuretten “ und für die dabei angewandte Redaktionsmethode ${ }^{5}$ Einvernehmen unter allen übrigen Mitgliedstaaten - Verfassungsfreunden wie Verfassungsskeptikern - zu erzielen. ${ }^{6}$ Das von der deutschen Ratspräsidentschaft erreichte Verhandlungsergebnis hat inzwischen sowohl im Europäischen Parlament als auch in den Parlamenten von 25 Mitgliedstaaten (darunter die Parlamente Frankreichs und der Niederlande) breite Zustimmung erhalten.

\section{Die Ausgangslage: EU-Reform am seidenen Faden}

Dennoch ist das für den 1. Januar 2009 vorgesehene Inkrafttreten der Reform von Lissabon, für das die Zustimmung aller 27 Mitgliedstaaten erforderlich ist, in Gefahr. In Irland, dem einzigen Mitgliedstaat, der für die Ratifizierung des Lissabon-Vertrags eine Volksabstimmung durchführte, stimmten am 12. Juni 2008 53,4 Prozent der Bevölkerung gegen das neue Vertragswerk. Seither hängt die Reform der Union am seidenen Faden. Zwar hat der Europäische Rat auf seiner Tagung vom 20. Juni 2008 in Brüssel beschlossen, das Ratifizierungsverfahren in den übrigen Ländern fortzusetzen und am 15. Oktober 2008 wieder auf die ,irische Frage ${ }^{6}$ zurückzukommen. ${ }^{7}$ Jedem ist aber klar, dass der Lissabon-Vertrag endgültig zu Grabe getragen werden muss, wenn die innerstaatliche Ratifizierung in auch nur einem weiteren Mitgliedstaat scheitern sollte. Die Zustimmung des britischen Oberhauses am 18. Juni 2008 zur EU-Reform sowie die Entscheidung des Londoner High Courts vom 25. Juni 2008, die Klage des britischen Multimillionärs Stuart Wheeler gegen den LissabonVertrag zügig abzuweisen, ${ }^{8}$ hatten daher eine wichtige positive Signalwirkung.

4 Vertrag über eine Verfassung für Europa vom 29. Oktober 2004, in: Amtsblatt der Europäischen Union, Nr. C 310 vom 16. Dezember 2004. Vgl. dazu Thomas Oppermann: Europäischer Verfassungskonvent und Regierungskonferenz 2002-2004, in: Deutsches Verwaltungsblatt 20/2004, S. 1264-1271; Jean-Claude Piris: The Constitution for Europe. A Legal Analysis, Cambridge 2006; Sylvia-Yvonne Kaufmann/Jens Wolfram: Die EU und ihre Verfassung. Linke Irrtümer und populäre Missverständnisse, Hamburg 2007.

5 Vgl. Rat der Europäischen Union: Mandat für die RK 2007, 26. Juni 2007, Ratsdokument 11218/07 (POLGEN 74), S. 1, Ziff. I.1: „Das Verfassungskonzept, das darin bestand, alle bestehenden Verträge aufzuheben und durch einen einheitlichen Text mit der Bezeichnung ,Verfassung “ zu ersetzen, wird aufgegeben.“ „Der EUV und der Vertrag über die Arbeitsweise der Union werden keinen Verfassungscharakter haben. Die in den Verträgen insgesamt verwendete Begrifflichkeit wird diese Änderung widerspiegeln: der Ausdruck ,Verfassung ‘ wird nicht verwendet [...]. Ebenso werden die geänderten Verträge keinen Artikel enthalten, in dem die Symbole der EU wie Flagge, Hymne und Leitspruch erwähnt werden." Ebenda, S. 3, Ziff. I.3. Hervorhebungen im Original.

6 Zur entscheidenden Rolle des deutschen EU-Ratsvorsitzes Andreas Maurer: Verhandlungen zum Reformvertrag unter deutschem Vorsitz, in: Aus Politik und Zeitgeschichte 43/2007, S. 3-8, hier S. 3.

7 Vgl. Rat der Europäischen Union: Europäischer Rat (Brüssel), 19./20. Juni 2008, Schlussfolgerungen des Vorsitzes, Ratsdokument 11018/08 (CONCL 2), S. 1 Ziff. 4 und 5.

8 Wheeler hatte argumentiert, dass das Partei-Manifest der Labour-Partei bei ihm ein schützenswertes Vertrauen (,legitimate expectation") begründet, dass der Verfassungsvertrag (mit dem der Lissabon-Vertrag weitgehend identisch sei) nur nach Abhaltung einer Volksabstimmung im Vereinigten Königreich ratifiziert werde. Die 
Zu den ,Wackelkandidaten' in der Europäischen Union zählt - neben der Tschechischen Republik $^{9}$ - nun ausgerechnet Deutschland. Dies liegt an zwei Verfassungsklagen, die mittlerweile beim Bundesverfassungsgericht (BVerfG) gegen das Zustimmungsgesetz zum Vertrag von Lissabon anhängig gemacht worden sind. Bereits im März hatte der CSUBundestagsabgeordnete Peter Gauweiler den Medien seine Absicht angezeigt, ${ }^{10}$ Verfassungsbeschwerde ${ }^{11}$ und Organklage ${ }^{12}$ gegen das Zustimmungsgesetz zu erheben. Entsprechende Schriftsätze hat Gauweiler am 23. Mai 2008 in Karlsruhe eingereicht. ${ }^{13}$ Unmittelbar nach dem positiven Ausgang der Bundestagsabstimmung über den Reformvertrag kündigte ferner der europapolitische Sprecher der Linksfraktion Diether Dehm eine eigene Verfassungsbeschwerde sowie eine Organklage der Fraktion Die Linke an, ${ }^{14}$ die am 23. Juni 2008 nach Karlsruhe übermittelt wurden. ${ }^{15}$

Diese Verfassungsklagen wecken ungute Erinnerungen an die Ratifizierung des Vertrags von Maastricht, der aus deutscher Sicht vor allem wegen der darin abgesicherten Unabhängigkeit der Europäischen Zentralbank (die noch über die der Bundesbank hinausgeht ${ }^{16}$ ) einen bemerkenswerten Verhandlungserfolg darstellte, dessen Inkrafttreten sich aber weniger infolge des damals in Dänemark zunächst gescheiterten Referendums ${ }^{17}$ als infolge von Verfassungsbeschwerden in Deutschland um mehr als zehn Monate verzögerte. Dies verunsicherte damals nicht nur die Finanzmärkte, sondern fügte vor allem der Glaubwürdigkeit deutscher Europapolitik auf Jahre erheblichen Schaden zu. Die Verfassungsbeschwerden gegen den Vertrag von Maastricht waren - ebenso wie jetzt die Klagen gegen den LissabonVertrag - mit Anträgen auf Erlass einer einstweiligen Anordnung gemäß § 32 Bundesverfassungsgerichtsgesetz (BVerfGG) verbunden, mit denen der Bundespräsident daran gehindert werden sollte, das deutsche Zustimmungsgesetz zu unterzeichnen und die Ratifikationsur-

Richter Stephen Richards und Colin Mackay wiesen diese Argumentation in ihrem schriftlichen Urteil wie folgt zurück: „We are satisfied that the claim lacks substantive merit and should be dismissed.“ Richards führte ferner aus: „Parliament has addressed the question whether there should be a referendum and, in passing the European Union Act 2008 has decided against one. [...] We have found nothing in the claimant's case to cast doubt on the lawfulness of ratifying the Lisbon Treaty without a referendum." Andrew Sparrow: Lisbon treaty: key findings from the high court judgment, in: guardian.co.uk, 25.06.2008, abrufbar unter: http://www.guardian.co.uk/world/2008/jun/25/eu.foreignpolicy1 (letzter Zugriff: 08.07.2008).

9 In der Tschechischen Republik ist das Verfassungsgericht durch den Senat mit der Prüfung der Verfassungsmäßigkeit des Vertrags von Lissabon befasst worden. Vgl. Rat der Europäischen Union: Europäischer Rat (Brüssel), 19./20. Juni 2008, Schlussfolgerungen des Vorsitzes, Ratsdokument 11018/08 (CONCL 2), S. 1, FN1: „Der Europäische Rat nimmt zur Kenntnis, dass in der Tschechischen Republik der Ratifizierungsprozess nicht abgeschlossen werden kann, bis das Verfassungsgericht eine positive Stellungnahme zur Vereinbarkeit des Vertrags von Lissabon mit der verfassungsmäßigen Ordnung der Tschechischen Republik abgegeben hat."

10 Vgl. Focus: Gauweiler contra EU, 10.03.2008, S. 11.

11 Vgl. Art. 93 Abs. 1 Nr. 4 a GG; $\$ \S 13$ Nr. 8a, 90 ff. BVerfGG.

12 Vgl. Art. 93 Abs. 1 Nr. 1 GG; $\S 13$ Nr. 5, 63 ff. BVerfGG.

13 Der Schriftsatz ist veröffentlicht unter: http://www.peter-gauweiler.de/pdf/Klage-Lissabon-Vertrag.pdf (letzter Zugriff: 08.07.2008). Der Klageschrift ist ein Gutachten des Freiburger Professors Dieter Murswiek beigefügt, das die Zulässigkeit und Begründetheit der Gauweiler-Klage analysiert. Abrufbar unter: http://www.peter-gauweiler.de/pdf/Vertr\%20Lissabon\%20Gutachten.pdf (letzter Zugriff: 08.07.2008).

14 Vgl. Der Tagesspiegel: Linkspolitiker Dehm klagt gegen EU-Vertrag von Lissabon, 22.04.2008, S. 4.

15 Zu beiden durch den Bielefelder Professor Andreas Fisahn vertretenen Klagen vgl. Tagesspiegel.de: Linke will EU-Vertrag stoppen, 26.06.2008, abrufbar unter: http://www.tagesspiegel.de/politik/deutschland/Linke-EUVertrag-Verfassungsklage;art122,2559641 (letzter Zugriff: 08.07.2008).

16 Hierzu eingehend Chiara Zilioli/Martin Selmayr: The Law of the European Central Bank, Oxford 2001, S. $32-$ 35.

17 In der Volksabstimmung vom 02.06.1992 über den Vertrag von Maastricht kam es in Dänemark zu 52,1 Prozent Nein-Stimmen bei einer Beteiligung von 83,1 Prozent. Am 18.05.1993 stimmte die dänische Bevölkerung in einem zweiten Referendum mit 56,8 Prozent Ja-Stimmen bei einer Beteiligung von 85,5 Prozent für die Ratifizierung des Vertrags. 
kunde zur Hinterlegung bei der italienischen Regierung (die seit den ,Römischen Verträgen “ von 1957 als Vertragssignatar fungiert ${ }^{18}$ ) auszufertigen. Beides unterließ der Bundespräsident damals von sich aus, um der Entscheidung des BVerfG nicht vorzugreifen. Erst als das BVerfG mit seinem Maastricht-Urteil vom 12. Oktober 1993 die Verfassungsbeschwerden als unbegründet abwies, ${ }^{19}$ konnte Deutschland als letzter Mitgliedstaat den neuen Vertrag ratifizieren.

\section{Das Dilemma der deutschen Verfassungsorgane}

Mehr noch als bei Maastricht stellen die gegen die Reform von Lissabon eingereichten Klagen das BVerfG und den Bundespräsidenten vor ein Dilemma. Sollen deutsche Verfassungsorgane wirklich die Ratifizierung des Lissabon-Vertrags aussetzen, bis das BVerfG in der Sache über die Klagen entschieden hat - auf die Gefahr hin, dass so aus Deutschland ein negatives Signal ausgesendet wird, das zum endgültigen Scheitern der EU-Reform führen könnte? Oder soll der Bundespräsident ungeachtet der Verfassungsklagen die Ratifikationsurkunde ausfertigen und soll die Bundesregierung durch deren Hinterlegung in Rom die völkerrechtliche Bindung Deutschlands gegenüber den übrigen Mitgliedstaaten herbeiführen, so aber riskieren, dass es im Fall einer stattgebenden Entscheidung des BVerfG zu einem unschönen Auseinanderfallen der verfassungsrechtlichen und der völkerrechtlichen Bindungen Deutschlands ${ }^{20}$ kommt? Sicherlich sollte man sich diese Entscheidung nicht mit dem Hinweis darauf leicht machen, dass das BVerfG unter Hunderten von völkerrechtlichen Verträgen bisher erst bei zwei Doppelbesteuerungsabkommen mit der Schweiz eine Unvereinbarkeit mit dem Grundgesetz festgestellt hat. ${ }^{21}$ Die Entscheidung der deutschen Verfassungsorgane kann aber auch nicht einfach nach dem Grundsatz ,im Zweifel für die Verfassungskläger` zu treffen sein, wie dies offenbar die Beschwerdeführer erwarten, wenn sie öffentlich den Eindruck erwecken, bereits mit der Einreichung ihrer Verfassungsbeschwerden das Ratifizierungsverfahren , gestoppt ${ }^{\star}$ zu haben. Denn Verfassungsbeschwerden haben - anders als verwaltungsgerichtliche Klagen (siehe $\S 80$ Abs. 1 Verwaltungsgerichtsordnung) - gerade keine automatisch aufschiebende Wirkung, ja das BVerfG ist noch nicht einmal verpflichtet, sie überhaupt zur Entscheidung anzunehmen, wenn sie keine ,grundsätzliche verfassungsrechtliche Bedeutung" haben (\$ 93a BVerfGG).

Einem Antrag auf einstweilige Anordnung hat das BVerfG nur stattzugeben, ,wenn dies zur Abwehr schwerer Nachteile, zur Verhinderung drohender Gewalt oder aus einem anderen wichtigen Grund zum gemeinen Wohl dringend geboten ist“" (§ 32 BVerfGG). Drohenden irreparablen Rechtsverletzungen des Beschwerdeführers hat das BVerfG dabei die grundsätzlich zu wahrende Autorität des parlamentarischen Gesetzgebers gegenüber zu stellen, welcher das Zustimmungsgesetz mit verfassungsändernder Mehrheit verabschiedet hat. Gerade bei Anträgen auf einstweilige Anordnung gegenüber dem Gesetzgeber wahrt das

18 Vgl. Art. 313 Abs. 1 Satz 2 EGV.

19 BVerfGE 89, 155.

20 Hierzu (anhand des Deutschland-Vertrags 1952) bereits BVerfGE 1, 396 (412 f.): „Die Ratifizierung, also die Hinterlegung der vom Bundespräsidenten ausgefertigten Ratifikationsurkunde, stellt die für die Bundesrepublik in der Regel bindende vertragliche Willenserklärung dar. Nach dem derzeitigen Stand des Völkerrechts kann die Möglichkeit nicht völlig ausgeschlossen werden, dass diese völkerrechtliche Bindung auch dann eintritt, wenn die Ratifikation unter Verletzung innerstaatlicher Verfassungsvorschriften zustande gekommen ist. Darüber, ob eine völkerrechtliche Bindung eingetreten ist, könnte kein deutsches Gericht, also auch nicht das Bundesverfassungsgericht, mit völkerrechtlicher Wirkung entscheiden. Es muss daher damit gerechnet werden, dass die Vertragspartner sich auf die völkerrechtliche Bindung berufen und damit vor einem etwa zuständigen internationalen Gericht obsiegen würden."

21 Vgl. BVerfGE 30, 272; BVerfGE 72, 200. 
BVerfG ,größte Zurückhaltung“‘22 und steht auf dem Standpunkt, dass bei der Prüfung der Begründetheit des Antrags auf einstweilige Anordnung „ein strenger Maßstab“23 anzulegen ist. Zu berücksichtigen hat das BVerfG auch, dass Deutschland dauerhaft bündnis- und integrationsunfähig würde, wenn zentrale außen- und europapolitische Entscheidungen einfach dadurch paralysiert werden könnten, dass ein umfangreicher Schriftsatz mit juristischen Formulierungen nach Karlsruhe geschickt wird. Die deutschen Verfassungsorgane sollten angesichts dieser Rechtslage sowie angesichts der europapolitischen Signalwirkung ihrer Entscheidung das Ratifizierungsverfahren nur dann aussetzen, wenn mit den Verfassungsklagen triftige Gründe vorgebracht werden, die in der Sache für eine Verfassungswidrigkeit des Vertrags von Lissabon sprechen.

Eine Eilentscheidung über diese schwierigen verfassungsrechtlichen und völkerrechtlichen Fragen hat Bundespräsident Horst Köhler dem BVerfG erspart. Am 30. Juni 2008 ließ der Bundespräsident erklären, er werde die Ratifikationsurkunde zum Vertrag von Lissabon bis zur Entscheidung des BVerfG über die Verfassungsmäßigkeit des Zustimmungsgesetzes nicht unterzeichnen. ${ }^{24}$ Damit entspreche er einer Bitte des BVerfG. Zugleich unterstreicht der Bundespräsident, dass er diese Entscheidung ,,ungeachtet des Ergebnisses seiner Prüfung des Zustimmungsgesetzes gem. Art. 82 Abs. $1 \mathrm{GG}^{\text {“25 }}$ getroffen habe. Mit dieser von der Verlautbarung des Bundespräsidenten anlässlich der Ratifizierung des Vertrags von Maastricht abweichenden Formulierung macht der Bundespräsident deutlich, dass er das Zustimmungsgesetz nicht - wie dies zum Beispiel beim Gesetz zur Neuregelung der Flugsicherung der Fall war ${ }^{26}$ - für verfassungswidrig hält, sondern allein aus Gründen der Verfassungsorgantreue gegenüber dem BVerfG seine Unterschrift noch nicht unter die Ratifizierungsurkunde gesetzt hat. Das deutsche Staatsoberhaupt will sich offensichtlich von den Verfassungsklägern nicht als ,Kronzeuge' gegen den Vertrag von Lissabon missbrauchen lassen.

\section{Zur Zulässigkeit der Verfassungsklagen: ,Kunstgriff‘ über Art. 38 Abs. 1 Satz 2 GG}

Obwohl die gegen die Reform von Lissabon klagenden Politiker von entgegengesetzten Enden des Parteienspektrums stammen, ist das zentrale juristische Argument ihrer Verfassungsklagen identisch. So erklärte der CSU-Abgeordnete Gauweiler gegenüber dem „Focus“: „Dieser Vertrag schwächt die Demokratie in der europäischen Politik, vor allem das Mitspracherecht der nationalen Parlamente“ ${ }^{27}$ während der Abgeordnete Dehm dem „Таgesspiegel“" erläuterte, dass es in der Klage der Linksfraktion im Kern darum ginge, ob Deutschland nach Ratifizierung des Lissabon-Vertrags noch ,eine parlamentarische Demokratie im Sinne des Grundgesetzes" sei. ${ }^{28}$ Rechtlich gesehen behaupten beide Beschwerdeführer damit eine Verletzung von Art. 38 Abs. 1 Satz 2 GG, wonach die Abgeordneten des Bundestages „Vertreter des ganzen Volkes“ zu sein haben.

22 Vgl. BVerfGE 85, 147 (171).

23 Ständige Rechtsprechung seit BVerfGE 3, 41 (44). Vgl. BVerfGE 46, 337 (340); BVerfGE 50, 37 (41).

24 Vgl. Der Bundespräsident: Bundespräsident Horst Köhler wird die Ratifikationsurkunde zum Vertrag von Lissabon bis zur Entscheidung des Bundesverfassungsgerichts über die Verfassungsmäßigkeit des Zustimmungsgesetzes zum Vertrag von Lissabon nicht unterzeichnen, Pressemitteilung des Bundespräsidialamts, 30.06.2008.

25 Ebenda.

26 Vgl. Der Bundespräsident: Bundespräsident Horst Köhler fertigt Gesetz zur Neuregelung der Flugsicherung nicht aus, Pressemitteilung des Bundespräsidialamts, 24.10.2006.

27 Focus: Gauweiler contra EU, S. 11.

28 Der Tagesspiegel: Linkspolitiker Dehm klagt, S. 4. 
Dahinter verbirgt sich ein verfassungsrechtlicher ,Kunstgriff“, der erforderlich ist, damit die Beschwerdeführer in Karlsruhe überhaupt Gehör finden können. Denn einzelne Bürger können Verfassungsbeschwerden nur mit der Behauptung erheben, selbst, gegenwärtig und unmittelbar in Grundrechten oder grundrechtgleichen Rechten verletzt worden zu sein. ${ }^{29}$ Eine ,Popularklage` zum BVerfG, mit der allein die Verletzung objektiven Rechts gerügt oder allgemeine Verfassungsprinzipien eingeklagt werden könnten - wie dies zum Beispiel in Bayern nach Art. 98 Satz 4 der Verfassung des Freistaats Bayern möglich ist -, gibt es in Deutschland auf Bundesebene nicht. Auf den Erlanger Professor Karl Albrecht Schachtschneider (und jetzigen Prozessvertreter Gauweilers ${ }^{30}$ ) und die von ihm 1992 betreute Verfassungsbeschwerde gegen den Maastricht-Vertrag geht allerdings die juristische Konstruktion zurück, dass Art. 38 Abs. 1 Satz 2 GG in Verbindung mit dem in Art. 20 Abs. 1 und 2 GG verankerten, von Art. 79 Abs. 3 GG für unantastbar erklärten Demokratieprinzip jedem Bürger ein verfassungsrechtlich geschütztes Recht darauf gibt, dass dem Bundestag im Rahmen der europäischen Integration Aufgaben und Befugnisse von Gewicht verbleiben müssen. Ein entsprechendes Bürgerrecht auf vom Bundestag verantwortete Politik hat das BVerfG in seinem Maastricht-Urteil grundsätzlich anerkannt, weshalb es die damalige auf Art. 38 Abs. 1 Satz 2 GG gestützte Verfassungsbeschwerde gegen das Zustimmungsgesetz zum Maastricht-Vertrag grundsätzlich für zulässig befand. ${ }^{31}$

Die entscheidende Passage im Maastricht-Urteil, auf die sich beide Verfassungskläger auch jetzt wieder berufen, lautet wie folgt: „Art. 38 GG schließt es im Anwendungsbereich des Art. 23 GG aus, die durch die Wahl bewirkte Legitimation von Staatsgewalt und Einflussnahme auf deren Ausübung durch die Verlagerung von Aufgaben und Befugnissen des Bundestages so zu entleeren, dass das demokratische Prinzip, soweit es Art. 79 Abs. 3 i.V.m. Art. 20 Abs. 1 und 2 GG für unantastbar erklärt, verletzt wird. “32 Oft übersehen wird, dass das BVerfG damit keineswegs , carte blanche" dafür gegeben hat, jeden denkbaren euroskeptischen Einwand gegen die europäische Integration über Art. 38 Abs. 1 Satz 2 GG in Karlsruhe geltend zu machen. Vielmehr beschränkt das BVerfG in der zitierten Passage des Maastricht-Urteils das mit Art. 38 Abs. 1 Satz 2 GG eröffnete Klagerecht auf den Fall, dass die Einflussnahme des Bundestages auf die Ausübung der Staatsgewalt auf eine Weise ,entleert“ wird, die das demokratische Prinzip, ,soweit es Art. 79 Abs. 3 i.V.m. Art. 20 Abs. 1 und 2 GG für unantastbar erklärt", verletzt. Das Demokratieprinzip ist also kein verfassungsrechtliches Argument dafür, die aktive Mitwirkung der Bundesrepublik Deutschland an der europäischen Integration - die von Art. 23 Abs. 1 Satz 1 GG ausdrücklich vorgesehen ist - zu behindern. Das BVerfG selbst gesteht zu, dass die Teilnahme Deutschlands an der Europäischen Union auch dazu führen kann, dass Entscheidungen auf europäischer Ebene getroffen werden, die so nicht von Deutschland gewollt oder sogar (im Fall von Mehrheitsentscheidungen) gegen seinen Willen zustande kommen: „Hierin eine Verletzung des grundgesetzlichen Demokratieprinzips zu sehen“, so das BVerfG 1993, ,widerspräche nicht nur der Integrationsoffenheit des Grundgesetzes, die der Verfassungsgeber des Jahres 1949 ge-

29 Ständige Rechtsprechung seit BVerfGE 1, 97 (101).

30 Schachtschneider hatte 2005 bereits die Klage Gauweilers gegen das Zustimmungsgesetz zum Verfassungsvertrag mit Argumenten vertreten, die fast wortlautidentisch sind mit den jetzt im Namen Gauweilers gegen den Lissabon-Vertrag eingereichten Schriftsatz. Vgl. Verfassungsbeschwerde gegen das Zustimmungsgesetz der Bundesrepublik Deutschland zum Vertrag vom 29. Oktober 2004 über eine Verfassung für Europa vom 27.05.2005, Aktenzeichen 2 BvR 839/05.

31 Kritisch Gerd Sturm, in: Michael Sachs (Hrsg.): GG-Kommentar, 3. Aufl., München 2003, Art. 93, Rdnr. 89: „eine gekünstelte Konstruktion, die mit dem Wesen der Verfassungsbeschwerde als ein ausschließlich dem Grundrechtsschutz dienendes Verfahren schwerlich vereinbar erscheint.“

32 BVerfGE 89, 155 (172). 
wollt und zum Ausdruck gebracht hat; es legte auch eine Vorstellung von Demokratie zugrunde, die jeden demokratischen Staat jenseits des Einstimmigkeitsprinzips integrationsunfähig machte. “33 Das BVerfG stellt deshalb fest: „Das Demokratieprinzip hindert mithin die Bundesrepublik Deutschland nicht an einer Mitgliedschaft in einer - supranational organisierten - zwischenstaatlichen Gemeinschaft. Voraussetzung der Mitgliedschaft ist aber, dass eine vom Volk ausgehende Legitimation und Einflussnahme auch innerhalb eines Staatenverbundes gesichert ist. "34 Bei der vom BVerfG geforderten Bewahrung des Demokratieprinzips im Rahmen der europäischen Integration geht es also nicht um einzelne, möglicherweise kritisch zu sehende Entscheidungen des Ministerrats, des Europäischen Parlaments, der Kommission oder des Europäischen Gerichtshofs, sondern um die Grundsatzfrage, ob insgesamt gesehen für den Bürger hinreichende demokratische Kontroll- und Einflussnahmemöglichkeiten gegenüber den auf europäischer Ebene zu treffenden Entscheidungen verbleiben.

Dass Art. 38 Abs. 1 Satz 2 GG gerade keine ,Allzweckwaffe gegen Brüssel` ist, sondern allein den Grundsatz der demokratisch-parlamentarischen Legitimation auch im Rahmen der Europäischen Union schützt, hat das BVerfG Professor Schachtschneider bereits zweimal ,schwarz auf weiß‘ mitgeteilt. So wies das BVerfG 1993 die von Schachtschneider vertretene, auf Art. 38 Abs. 1 Satz 2 GG gestützte Verfassungsbeschwerde gegen den MaastrichtVertrag als ,unbegründet‘ ab. Der Gewährleistungsinhalt des Art. 38 Abs. 1 Satz 2 GG „wird durch das Zustimmungsgesetz, wie sich aus dem Inhalt des Vertrags ergibt, nicht verletzt“, stellte das BVerfG dabei ausdrücklich fest. ${ }^{35}$ Noch deutlicher wurde das BVerfG, als Schachtschneider 1998 erneut, diesmal gemeinsam mit drei weiteren Universitätsprofessoren, Verfassungsbeschwerde gegen die bevorstehende Beschlussfassung des Bundestages über die Teilnahme Deutschlands an der Währungsunion erhob. ${ }^{36}$ Diese Verfassungsbeschwerde verwarf das BVerfG in seinem Euro-Beschluss vom 31. März $1998^{37}$ ohne mündliche Verhandlung gemäß $§ 24$ BVerfGG (sogenannte ,a limine'-Abweisung). Dabei ließen die Verfassungsrichter die Frage der Zulässigkeit der Verfassungsbeschwerde ausdrücklich offen. Denn sie sahen die von Schachtschneider vertretene Beschwerde ,als jedenfalls offensichtlich unbegründet“ an, da die Mitwirkung Deutschlands an der Währungsunion,,im Vertrag von Maastricht vorgesehen sowie mit Art. 23 und Art. 88 Satz 2 GG grundsätzlich gestattet ist". ${ }^{38}$ Erneut scheiterte Schachtschneider damit in Karlsruhe mit seiner verfassungsrechtlichen Argumentation. Vor diesem Hintergrund ist jetzt die von Schachtschneider vertretene Gauweiler-Beschwerde - und auch die parallel argumentierende Klage der Linksfraktion - als der dritte Versuch Schachtschneiders zu werten, um - teilweise unter Wiederholung seiner bereits in den vorhergehenden Verfahren vom BVerfG zurückgewiesenen Argumente - das Fortschreiten der von ihm abgelehnten, von Bundestag und Bundesrat aber gebilligten europäischen Einigung doch noch aufzuhalten.

Bei den Beschwerdeführern selbst scheinen erhebliche Zweifel daran zu bestehen, ob es ihnen mithilfe des ,Kunstgriffs‘ über Art. 38 Abs. 1 Satz 2 GG noch einmal gelingt, die Zulässigkeitshürde in Karlsruhe zu überwinden. Dies zeigt der Umstand, dass sie ihre Argu-

33 BVerfGE 89, 155 (183).

34 BVerfGE 89, 155 (184).

35 BVerfGE 89, 155 (181).

36 Die vor allem auf Schachtschneider zurückgehende juristische Argumentation dieser Beschwerde ist nachzulesen in Wilhelm Hankel/Wilhelm Nölling/Karl Albrecht Schachtschneider/Joachim Starbatty: Die Euro-Klage. Warum die Währungsunion scheitern muss, Hamburg 1998, 192-283.

37 BVerfGE 97, 350.

38 BVerfGE 97, 350 (368). 
mente gegen den Vertrag von Lissabon zugleich in ihrer Eigenschaft als Bundestagsabgeordnete im Organstreitverfahren vorbringen. Der Organstreit ermöglicht den Verfassungsorganen grundsätzlich auch die Geltendmachung objektiver Rechtsverletzungen. Allerdings begrenzt $\S 63$ BVerfGG den Kreis der Antragsteller im Organstreit auf den Bundespräsidenten, den Bundestag, den Bundesrat, die Bundesregierung und die im GG oder in den Geschäftsordnungen des Bundestages und des Bundesrates mit eigenen Rechten ausgestatteten Teile dieser Organe. Einzelne Abgeordnete des Bundestages können nur dann ausnahmsweise ein Organstreitverfahren beantragen, wenn die streitigen Maßnahmen sie gerade in ihrem Status als Abgeordnete (beispielsweise durch Beschneidung des Rederechts oder vorzeitige Auflösung des Bundestages) verletzen. ${ }^{39}$ Nicht zulässig ist es im Organstreitverfahren dagegen, dass ein einzelner Abgeordneter in Prozessstandschaft Rechte des gesamten Bundestages geltend macht. ${ }^{40}$ Das BVerfG wird daher den von Gauweiler in seiner Eigenschaft als Bundestagsabgeordneter angestrengten Organstreit als unzulässig abweisen, da Gauweiler mit seiner Klage gewissermaßen für den Bundestag dessen Recht geltend machen will, an der Beschlussfassung in europäischen Fragen auch in Zukunft maßgeblich beteiligt zu sein. Auch die Zulässigkeit des von der Linksfraktion beantragten Organstreits ist fraglich. Zwar gesteht das BVerfG grundsätzlich auch Fraktionen als Teilen des Bundestages das Recht zu, im Organstreitverfahren Rechte des Bundestages gegenüber der Bundesregierung geltend zu machen. ${ }^{41}$ In dem jetzt gegen das Zustimmungsgesetz zum Vertrag von Lissabon beantragten Organstreitverfahren versucht die Linksfraktion allerdings, die Verletzung von Rechten des Bundestages geltend zu machen, nachdem der Bundestag selbst diesem Zustimmungsgesetz mit verfassungsändernder Mehrheit zugestimmt hat. Die Linksfraktion beruft sich also gegenüber dem Bundestag auf eine Verletzung von Rechten des Bundestages, weshalb die Zulässigkeit ihres Antrags jedenfalls zweifelhaft ist.

\section{Zur Begründetheit der Verfassungsklagen}

Sollten die Verfassungsklagen Gauweilers und der Linksfraktion trotz der genannten Bedenken vom BVerfG jedenfalls teilweise für zulässig angesehen werden, stellt sich die Frage nach ihrer Begründetheit. Ist die von Gauweiler und der Linksfraktion aufgestellte Behauptung, der Bundestag werde durch den Vertrag von Lissabon geschwächt, in der Sache verfassungsrechtlich überzeugend? Davon kann nur die Rede sein, wenn man den Inhalt des neuen Vertrags überhaupt nicht zur Kenntnis nimmt.

Sicherlich kann man in der Entwicklung der Europäischen Union in den vergangenen Jahrzehnten eine (auch von den deutschen Verfassungsorganen mitgetragene) schrittweise Verlagerung von Entscheidungsbefugnissen auf die Unionsebene erkennen. Der LissabonVertrag setzt diesen Prozess aber nicht fort. Erstmals konzentriert sich ein neuer Vertrag nicht auf den weiteren Ausbau der EU-Kompetenzen, sondern macht die Zuständigkeit der Mitgliedstaaten zur Regel (Art. 4 Abs. 1 EUV), grenzt die EU-Kompetenzen deutlicher ab als je zuvor (Art. 5 EUV), erklärt Unionszuständigkeiten ausdrücklich für rückholbar (Art. 2

39 BVerfGE 10, 4 (10); BVerfGE 2, 143 (166); BVerfGE 60, 374 (378); BVerfGE 62, 1 (32); BVerfGE 70, 324 (350).

40 So ausdrücklich BVerfGE 90, 286 (343): „Die Antragsteller sind auch nicht berechtigt, im Wege der Prozeßstandschaft Rechte des Bundestages geltend zu machen. Die Prozeßstandschaft ist eine Ausnahme von dem allgemeinen verfahrensrechtlichen Grundsatz, daß Verfahrensbeteiligte nur eigene Rechte geltend machen können; sie bedarf daher einer ausdrücklichen gesetzlichen Zulassung (vgl. BVerfGE 60, 319 [325]). Eine solche findet sich in $\S \S 63,64$ Abs. 1 BVerfGG; sie bezieht sich jedoch nur auf die Prozeßstandschaft eines Organteils für das Gesamtorgan [...], berechtigt aber nicht den einzelnen Abgeordneten."

41 So BVerfGE 90, 286 (336). 
Abs. 2 Satz 3 AEUV) und anerkennt zudem für jeden Mitgliedstaat ein Recht zum Austritt aus der Union (Art. 50 EUV). Einer ,schleichenden Verbundesstaatlichung' der Europäischen Union ist damit ein Riegel vorgeschoben. Zugleich wird die parlamentarische Kontrolle der Ausübung der EU-Kompetenzen erheblich verstärkt und zwar auf nationaler wie auf europäischer Ebene.

\section{Die Parlamentarisierung Europas im Lissabon-Vertrag}

Die nationalen Parlamente werden durch den Lissabon-Vertrag keineswegs geschwächt, wie Gauweiler und die Linksfraktion unisono in ihren Verfassungsklagen behaupten. Vielmehr leistet der neue Vertrag den mit Abstand stärksten Beitrag zur Parlamentarisierung der europäischen Entscheidungsverfahren seit Gründung der Europäischen Gemeinschaften in den 1950er Jahren.

(1) Als erster europäischer Vertrag verankert der Vertrag von Lissabon den Grundsatz der „repräsentativen Demokratie“ (Art. 10 Abs. 1 EUV) ausdrücklich im EU-Primärrecht. Der neue Art. 10 EUV folgt dabei einem zweispurigen Demokratieverständnis, wie es das BVerfG bereits in seinem Maastricht-Urteil 1993 vorgezeichnet hat. Dort hieß es: „Im Staatenverbund der Europäischen Union erfolgt [...] demokratische Legitimation notwendig durch die Rückkoppelung des Handelns europäischer Organe an die Parlamente der Mitgliedstaaten; hinzutritt - im Maße des Zusammenwachsens der europäischen Nationen zunehmend - innerhalb des institutionellen Gefüges der Europäischen Union die Vermittlung demokratischer Legitimation durch das von den Bürgern der Mitgliedstaaten gewählte Europäische Parlament. “42 Als ob das BVerfG selbst die Feder geführt hätte, heißt es künftig in Art. 10 Abs. 2 EUV: „Die Bürgerinnen und Bürger werden auf Unionsebene unmittelbar im Europäischen Parlament vertreten. Die Mitgliedstaaten werden im Europäischen Rat von ihrem jeweiligen Staats- oder Regierungschef und im Rat von ihrer jeweiligen Regierung vertreten, die ihrerseits in demokratischer Weise gegenüber ihrem nationalen Parlament oder gegenüber ihren Bürgerinnen und Bürgern Rechenschaft ablegen müssen.“

(2) Im Einklang mit der neuen ,Demokratiedefinition à la Karlsruhe“ werden die nationalen Parlamente im neuen Vertrag in Art. 12 EUV noch vor dem Europäischen Parlament (das erst in Artt. 13 und 14 EUV behandelt wird) genannt und durch diese neue Vorschrift mit eigenen Informations-, Kontroll- und Mitwirkungsrechten ausgestattet. Zwei dem EUV durch den Reformvertrag beigefügte Protokolle über die Rolle der nationalen Parlamente ${ }^{43}$ (sogenanntes ,Parlamente-Protokoll ${ }^{\circ}$ ) und die Anwendung des Subsidiaritätsprinzips ${ }^{44}$ (sogenanntes ,Subsidiaritätsprotokoll ${ }^{`}$ ) konkretisieren ausführlich diese parlamentarischen Rechte.

(3) Der Vertrag von Lissabon macht die nationalen Parlamente zu, Wächtern der Subsidiarität' in der Europäischen Union. Künftig muss jedes nationale Parlament direkt von der Europäischen Kommission über neue Gesetzesvorschläge informiert werden, ist also nicht mehr wie bisher darauf angewiesen, diese von der nationalen Regierung weitergeleitet zu bekommen. Jedes nationale Parlament erhält zugleich das Recht, innerhalb von acht Wochen Subsidiaritätsbedenken geltend zu machen, also bereits ganz am Anfang des Gesetzgebungsverfahrens darauf hinzuweisen, dass bestimmte Entscheidungen besser auf nationaler,

42 BVerfGE 89, 155 (185 f.).

43 Protokoll über die Rolle der nationalen Parlamente in der Europäischen Union, in: Amtsblatt der Europäischen Union, Nr. C 306 vom 17. Dezember 2007, S. 148-150.

44 Protokoll über die Anwendung der Grundsätze der Subsidiarität und der Verhältnismäßigkeit, in: Amtsblatt der Europäischen Union, Nr. C 306 vom 17. Dezember 2007, S. 150-152. 
regionaler oder lokaler Ebene getroffen werden können (Art. 5 Abs. 3 EUV). Werden solche Subsidiaritätsrügen von einem Drittel ${ }^{45}$ der nationalen Parlamente geltend gemacht - man spricht vom Verfahren der, gelben Karte ‘-, so ist die Kommission zur Überprüfung des Gesetzesvorschlags verpflichtet. Bei justizpolitischen oder strafrechtlichen Vorhaben reichen hierfür Subsidiaritätsrügen von einem Viertel ${ }^{46}$ der nationalen Parlamente (Art. 7 Abs. 2 Subsidiaritätsprotokoll). Teilt die Mehrheit ${ }^{47}$ der nationalen Parlamente die Subsidiaritätsbedenken, zeigen sie also die sogenannte ,orangefarbene Karte', so können sie sogar erreichen, dass das Gesetzgebungsverfahren noch in erster Lesung abgebrochen wird (Art. 7 Abs. 3 Subsidiaritätsprotokoll ${ }^{48}$ ) - was im Vergleich zum Verfassungsvertrag eine weitere Stärkung der nationalen Parlamente darstellt. In Staaten mit einem Zweikammersystem hat dabei gemäß Art. 7 Abs. 1 UAbs. 2 Satz 2 Subsidiaritätsprotokoll jede Kammer des nationalen Parlaments eine eigene Stimme, sodass in Deutschland sowohl der Bundestag als auch der Bundesrat selbstständig Subsidiaritätsrügen erheben können. ${ }^{49}$

(4) Jedes nationale Parlament erhält im Lissabon-Vertrag das Recht, gegen EU-Rechtsakte, die aus seiner Sicht gegen das Subsidiaritätsprinzip verstoßen, direkt vor dem Europäischen Gerichtshof Subsidiaritätsklage zu erheben (Art. 8 Subsidiaritätsprotokoll). Dieses Klagerecht steht in Deutschland gemäß dem zusammen mit der Reform von Lissabon beschlossenen Art. 23 Abs. 1a Satz 2 GG sowohl dem Bundestag als auch dem Bundesrat zu..$^{50}$ Dabei muss der Bundestag Subsidiaritätsklage bereits dann erheben, wenn dies von einem Viertel seiner Mitglieder beantragt wird. Damit ist es künftig auch einer parlamentarischen Minderheit möglich, ihre Subsidiaritätsbedenken auf Unionsebene gerichtlich geltend zu machen.

(5) Auch wenn der neue Vertrag Mehrheitsentscheidungen zur Regel macht, bleibt es auch in Zukunft in zentralen außen- und sicherheitspolitischen Entscheidungen beim Erfordernis der Einstimmigkeit im EU-Ministerrat, sodass insofern jedes nationale Parlament über seine Regierung bestimmenden Einfluss behält. Dies gilt insbesondere für mögliche EU-Militärmissionen, die nur dann mit deutscher Beteiligung stattfinden dürfen, wenn Deutschland dazu im Rat seine Zustimmung erteilt (Art. 42 Abs. 4 Satz 1, Art. 46 Abs. 6 EUV). Der neue Vertrag ermöglicht es somit, den wehrverfassungsrechtlichen Parlaments-

45 Art. 7 Abs. 1 UAbs. 2 Satz 1 Subsidiaritätsprotokoll weist jedem nationalen Parlament zwei Stimmen zu. Für eine ,gelbe Karte“ ist mindestens ein Drittel der Gesamtzahl der den nationalen Parlamenten zugewiesenen Stimmen erforderlich, bei 27 Mitgliedstaaten also 18 von 54 Stimmen.

46 Bei 27 Mitgliedstaaten also 13 von 54 Stimmen.

47 Eine solche ,orangefarbene Karte' erfordert die einfache Mehrheit der Gesamtzahl der den nationalen Parlamenten nach Art. 7 Abs. 1 UAbs. 2 Satz 1 Subsidiaritätsprotokoll zugewiesenen Stimmen, also bei 27 Mitgliedstaaten 28 von 54 Stimmen.

48 Die ,orangefarbene Karte ' löst zunächst eine Rechtspflicht der Kommission aus, ihren Vorschlag zu überprüfen. Will die Kommission an dem Vorschlag unverändert festhalten, so hat sie die Beachtung des Subsidiaritätsprinzips in einer gesonderten begründeten Stellungnahme darzulegen. Die Stellungnahme der Kommission wird anschließend zusammen mit den negativen Stellungnahmen der nationalen Parlamente dem Unionsgesetzgeber (Europäisches Parlament und Rat) vorgelegt, der vor Abschluss der ersten Lesung prüft, ob der Gesetzgebungsvorschlag mit dem Subsidiaritätsprinzip im Einklang steht. Teilen dabei nur 55 Prozent der Mitglieder des Rates oder das Europäische Parlament mit der Mehrheit der abgegebenen Stimmen die Auffassung der nationalen Parlamente, dann wird der Kommissionsvorschlag nicht weiterverfolgt. Die nationalen Parlamente können durch das Ziehen der , orangefarbenen Karte" also ein Verfahren auslösen, das bereits in der ersten Lesung den Gesetzgebungsvorschlag zu Fall bringt, selbst wenn eine der beiden Kammern des Unionsgesetzgebers den Vorschlag mit der Kommission als notwendig ansieht.

49 Vgl. auch § 2 Gesetz über die Ausübung der Rechte des Bundestages und des Bundesrates aus dem Vertrag von Lissabon vom 13. Dezember 2007 zur Änderung des Vertrags über die Europäische Union und des Vertrags zur Gründung der Europäischen Gemeinschaft, in: Bundestagsdrucksache 16/8489 vom 11.03.2008.

50 Vgl. auch $\S 3$ Gesetz über die Ausübung der Rechte des Bundestages und des Bundesrates aus dem Vertrag von Lissabon vom 13. Dezember 2007 zur Änderung des Vertrags über die Europäische Union und des Vertrags zur Gründung der Europäischen Gemeinschaft, ebenda. 
vorbehalt für derartige Bundeswehreinsätze, den das BVerfG zuletzt in seiner neuen AWACS-Entscheidung bekräftigt hat, ${ }^{51}$ ohne Einschränkungen zu beachten. Ohne Zustimmung des Bundestages kann keine EU-Militärmission mit deutscher Beteiligung stattfinden.

(6) Auch in Zukunft bleiben Vertragsänderungen, Beitritte neuer Mitgliedstaaten und Beschlüsse über die Finanzmittel der Europäischen Union ratifizierungsbedürftig, treten also nur dann in Kraft, wenn jedes nationale Parlament dazu seine Zustimmung gegeben hat (Art. 48 Abs. 4, Art. 49 Abs. 2 EUV, Art. 311 Abs. 3 Satz 3 AEUV).

(7) Verfahrensrechtlich erschwert wird durch die Reform von Lissabon die Anwendung der sogenannten ,Flexibilitätsklausel ' (bisher Art. 308 EGV, künftig Art. 352 AEUV), welche es der Europäischen Union ermöglicht, Beschlüsse ausnahmsweise auch dann zu fassen, wenn keine spezielle Rechtsgrundlage in den Verträgen vorgesehen ist. Während Art. 308 EGV heute hierfür nur die Anhörung des Europäischen Parlaments fordert, erlaubt Art. 352 Abs. 1 AEUV die Anwendung der Flexibilitätsklausel nur dann, wenn das Europäische Parlament dazu seine Zustimmung gegeben hat. Eine zusätzliche Einschränkung ergibt sich aus den im Lissabon-Vertrag neu vorgesehenen Kontrollrechten der nationalen Parlamente, die bei der Anwendung der Flexibilitätsklausel von der Kommission gemäß Art. 352 Abs. 2 AEUV eigens darauf hinzuweisen sind, dass sie von ihnen angenommene Verletzungen des Subsidiaritätsprinzips mit , gelben“ und , orangefarbenen Karten ' rügen und notfalls gerichtlich beanstanden können. Ferner stellt Art. 352 Abs. 3 AEUV klar, dass die Anwendung der ,Flexibilitätsklausel ' keine Maßnahmen erlaubt, die zu einer Harmonisierung von nationalen Rechtsvorschriften führen, wenn die Verträge eine solche Harmonisierung an anderer Stelle gerade ausschließen; damit wird sichergestellt, dass Befugnisse der nationalen Gesetzgeber in Bereichen, die von den Verträgen nicht auf die Europäische Union übertragen worden sind, über die ,Flexibilitätsklausel ' nicht überlagert oder gar verdrängt werden. ${ }^{52}$

(8) Jedes einzelne nationale Parlament ${ }^{53}$ erhält schließlich durch den Vertrag von Lissabon ein innerhalb von sechs Monaten ausübbares Vetorecht (, rote Karte) gegenüber Vertragsänderungen, die nicht, wie sonst üblich, von einer Regierungskonferenz, sondern einstimmig vom Europäischen Rat mit Zustimmung des Europäischen Parlaments beschlossen werden. Damit können Bundestag und Bundesrat künftig vor allem verhindern, dass in einem Politikfeld von der Einstimmigkeit im Rat zu Mehrheitsentscheidungen übergegangen wird (Art. 48 Abs. 7 EUV). Auf vergleichbare Weise kann jedes einzelne nationale Parlament ein Veto gegenüber einer Europäisierung des Familienrechts einlegen (Art. 81 Abs. 3 AEUV). Gegen den Willen auch nur eines einzigen nationalen Parlaments kann daher eine solch vereinfachte Vertragsänderung nicht zustande kommen. Die nationalen Parlamente erhalten mit der, roten Karte' die rechtliche Möglichkeit, sich gegen Veränderungen im Machtgefüge auf europäischer Ebene zu stellen, und behalten so eine starke Einflussmöglichkeit auf die künftige, in den ,Passerelle-Klauseln“ im Vertrag von Lissabon bereits angelegte Weiterentwicklung der Europäischen Union. ${ }^{54}$

51 BVerfG: Urteil des Zweiten Senats vom 07.05.2008, Aktenzeichen 2 BvE 1/03. Zuvor bereits BVerfGE 89, 38; BVerfGE 90, 286 (381 f.).

52 Dies übersieht die Gauweiler-Klage, wenn sie Art. 352 AEUV zur ,Kompetenz-Kompetenz ' hochstilisiert. Vgl. Gauweiler-Klage, 2008, S. 308-309.

53 Nicht ganz klar wird aus dem Vertragstext, ob das nationale Parlament in seiner Gesamtheit oder auch sogar eine einzelne Kammer gemeint ist. Gegen die Kammerlösung spricht dabei Art. 8 Protokoll über die Rolle der nationalen Parlamente, der die einzelnen Parlamentskammern nur in das nach Art. 6 Protokoll über die Rolle der nationalen Parlamente bestehende Informationsrecht im Vertragsänderungsverfahren einbezieht, während es für die Ausübung des Vetorechts nach Art. 12 Buchstabe c i.V.m. Art. 48 Abs. 7 UAbs. 3 EUV an einer vergleichbaren Regelung fehlt.

54 Vgl. auch § 4 Abs. 3 Gesetz über die Ausübung der Rechte des Bundestages und des Bundesrates aus dem Vertrag von Lissabon vom 13. Dezember 2007 zur Änderung des Vertrags über die Europäische Union und des Vertrags zur Gründung der Europäischen Gemeinschaft, in: Bundestagsdrucksache 16/8489 vom 11.03.2008. 
Insgesamt werden die nationalen Parlamente durch den Vertrag von Lissabon von bisher nur mittelbar beteiligten, eher fernen Zuschauern des Unionsgeschehens zu unmittelbaren, mit eigenen justitiablen Mitwirkungsrechten ausgestatteten Akteuren im EU-Entscheidungsprozess. Zu Recht hat der französische Verfassungsrat in seiner Entscheidung zum Lissabon-Vertrag vom 20. Dezember 2007 von ,neuen Prärogativen der nationalen Parlamente im Rahmen der Europäischen Union“" gesprochen. ${ }^{55}$ Auch der Präsident des BVerfG HansJürgen Papier hat in einem Vortrag an der Humboldt-Universität zu Berlin Anfang des Jahres die Reformen von Lissabon insofern als „Stärkung des demokratischen Elements“ ${ }^{\text {“56 ge- }}$ wertet und es insbesondere begrüßt, dass der Vertrag von Lissabon die nationalen Parlamente als „zweiten Legitimationsstrang“ der Europäischen Union „substanziell stärkt“ und „die nationalen Parlamente selbst in den Rang europäischer Akteure“ erhebt. ${ }^{57}$ Jedenfalls juristisch wird durch die neuen Mitwirkungsrechte ausgeschlossen, dass künftig eine Regierung ihr nationales Parlament durch Beschlüsse in Brüssel vor vollendete Tatsachen stellt. Die Eröffnung eines eigenen Bundestagsbüros in Brüssel Anfang $2007^{58}$ zeigt, dass das deutsche Parlament von seinen neuen Rechten aktiv Gebrauch machen will.

\section{Das Europäische Parlament wird ,Mit-Gesetzgeber ' der Europäischen Union}

Eine weitere zentrale Neuerung, die der Lissabon-Vertrag bewirken soll, ist die grundsätzliche Gleichberechtigung von Europäischem Parlament und EU-Ministerrat in der Gesetzgebung wie in Budgetfragen. Dies ist auch anhand der verfassungsrechtlichen Wertungsmaßstäbe des GG von nicht zu unterschätzender Bedeutung, seit das BVerfG im Maastricht-Urteil anerkannt hat, dass demokratische Legitimation in der Europäischen Union nicht nur von den nationalen Parlamenten, sondern ,zunehmend“ auch „durch das von den Bürgern der Mitgliedstaaten gewählte Europäische Parlament" vermittelt wird. ${ }^{59}$

Dem heute erreichten Stand der europäischen Integration entspricht es daher, dass das bisherige Mitentscheidungsverfahren, das bereits seit Maastricht in einigen Politikbereichen eine gleichberechtigte Mitwirkung des Europäischen Parlaments an der Gesetzgebung vorsieht, künftig zum ordentlichen Gesetzgebungsverfahren wird, das in 95 Prozent aller Fälle zur Anwendung kommt. Dies verschafft dem Europäischen Parlament ein Mitentscheidungsrecht über wichtige Politikfelder wie zum Beispiel die Landwirtschaftspolitik, ${ }^{60}$ die Energiepolitik, ${ }^{61}$ das Währungsrecht für den Euro ${ }^{62}$ und die Umsetzung der gemeinsamen Handelspolitik. ${ }^{63}$ Besonders bemerkenswert ist die Stärkung des Europäischen Parlaments bei der Gesetzgebung über die justizielle und polizeiliche Zusammenarbeit in Strafsachen, die bisher als, dritte Säule ' der Union weitgehend ohne parlamentarische Mitwirkung stattfand, in Zukunft aber in das allgemeine Entscheidungsverfahren der Union einbezogen wird und damit der Kontrolle sowohl des Europäischen Parlaments als auch der nationalen Parlamente unterliegt. ${ }^{64}$

55 Le Conseil Constitutionnel: Décision n²007-560 DC, Traité de Lisbon modifiant le traité sur 1‘Union europénne et le traité instituant la Communauté europénne, vom 20.12.2008, Ziff. 28. Eigene Übersetzung, im Original: „nouveaux prérogatives reconnues aux parlements nationaux dans le cadre de 1'Union.“ Vgl. Le Conseil Constitutionnel: Décision n 2004-505 DC, Traité établissant une constitution pour 1'Europe, vom 19.11.2004, Ziff. 37-41.

56 Hans-Jürgen Papier: Europas neue Nüchternheit: Der Vertrag von Lissabon, Vortrag gehalten an der Humboldt-Universität zu Berlin am 21.02.2008, in: Forum Constitutionis Europae 1/2008, S. 4.

57 Ebenda, S. 5.

58 Vgl. Annette Sach: Mit offenen Augen und Ohren, in: Das Parlament, 12.02.2007.

59 BVerfGE 89, 155 (185 f.).

60 Art. 43 Abs. 2 AEUV.

61 Art. 194 Abs. 2 AEUV.

62 Art. 133 AEUV.

63 Art. 207 Abs. 2 AEUV.

64 Art. 82 Abs. 2; Art. 83 Abs. 1 UAbs. 1; Art. 85 Abs. 1 UAbs. 2; Art. 88 Abs. 2 sowie Art. 69 AEUV. 
Die rechtliche Bedeutung der Aufwertung des Europäischen Parlaments zur Ersten Kammer des Unionsgesetzgebers erschließt sich zur Gänze erst bei einer systematischen Zusammenschau der neuen Befugnisse des Parlaments mit den neu gefassten Vertragsbestimmungen zu den Rechtsakten der Union. Der Vertrag von Lissabon führt hier erstmals eine Art Normenhierarchie ein, ${ }^{65}$ die zwischen „Gesetzgebungsakten“ (Art. 289 Abs. 3 AEUV) und Rechtsakten ohne Gesetzescharakter, insbesondere an die Kommission delegierte Rechtsakte (Art. 290 AEUV) sowie Durchführungsrechtsakte von Kommission und Rat (Art. 291 AEUV), unterscheidet. Gemäß Art. 289 Abs. 3 AEUV gelten dabei nur die im (ordentlichen oder besonderen) Gesetzgebungsverfahren gemäß Art. 289 Abs. 1, 2 AEUV erlassenen Normen als Gesetzgebungsakte. Ein Rechtsakt, der ohne Beteiligung des Europäischen Parlaments erlassen worden ist, hat also in Zukunft keine Gesetzesqualität und damit als ,,sonstiger Rechtsakt ohne Gesetzescharakter“ oder „Rechtsakt mit Verordnungscharakter“ zu gelten. Zwar verbindet das Unionsprimärrecht mit der Gesetzesqualität keine direkten rechtlichen Folgen. ${ }^{66}$ Angesichts der Bedeutung, die dem Grundsatz der repräsentativen Demokratie gemäß Art. 10 Abs. 2 EUV zukommt, ist allerdings anzunehmen, dass im Fall einer Kollision zwischen einem Gesetzgebungsakt und einem Rechtsakt ohne Gesetzescharakter grundsätzlich ersterem der Vorrang einzuräumen ist. ${ }^{67}$ Dies kann zum Beispiel im Rahmen der Landwirtschaftspolitik bedeutsam werden, wo Gemeinsame Marktorganisationen in Zukunft gemäß Art. 43 Abs. 2 AEUV im ordentlichen Gesetzgebungsverfahren erlassen werden, während Art. 43 Abs. 3 AEUV den Rat ermächtigt, allein und ohne Beteiligung des Europäischen Parlaments die Maßnahmen zu erlassen, die beispielsweise zur Festsetzung der Preise, der Abschöpfungen und der Beihilfen erforderlich sind. Denkbar ist auch, dass die Nutzung der originären Rechtsetzungsbefugnisse, die der Kommission im Bezug auf öffentliche Unternehmen und Dienstleistungen nach allgemeinem wirtschaftlichen Interesse gemäß Art. 106 Abs. 3 AEUV zustehen, ${ }^{68}$ mit der neuen Befugnis des Gemeinschaftsgesetzgebers gemäß Art. 14 Satz 2 AEUV in Konflikt gerät, Grundsätze und Bedingungen für das Funktionieren der Dienste von allgemeinem wirtschaftlichen Interesse festzulegen. Die im neuen Unionsprimärrecht angelegte Normenhierarchie kann schließlich Auswirkungen auf das Verhältnis zwischen dem in Zukunft gemäß Art. 133 AEUV vom Europäischen Parlament und dem Rat gemeinsam erlassenen Währungsrecht für den Euro und den von der Europäischen Zentralbank (EZB) auf der Grundlage ihrer originären Rechtsetzungsbefugnisse (Art. 282 Abs. 4 AEUV i.V.m. Art. 132 Abs. 1 AEUV sowie Art.

65 Hierzu instruktiv Nettesheim, der jedenfalls anhand der im EU-Verfassungsvertrag vorgenommenen (inhaltsgleichen) Normenhierarchie von einem „Gewinn an Transparenz“ spricht. Vgl. Martin Nettesheim: Normenhierarchie im EU-Recht, in: Europarecht 6/2006, S. 737-772, hier S. 768. Eine Normenhierarchie hatte bereits die der Schlussakte von Maastricht beigefügte Erklärung Nr. 16 zur Rangordnung der Rechtsakte der Gemeinschaft für die ,Maastricht II'-Regierungskonferenz gefordert, damals aber noch nicht umgesetzt. Vgl. Erklärung zur Rangordnung der Rechtsakte der Gemeinschaft zum Vertrag über die Europäische Union, in: Amtsblatt der Europäischen Gemeinschaften, Nr. C 191 vom 29. Juli 1992, S. 101.

66 Vgl. aber die Neufassung der individuellen Klagebefugnis in Art. 230 Abs. 4 AEUV, die bei „Rechtsakten mit Verordnungscharakter" den Zugang zum Europäischen Gerichtshof erleichtert.

67 Für eine ,normenhierarchische Abstufung“ anhand des EU-Verfassungsvertrags siehe auch Martin Nettesheim: Normenhierarchie im EU-Recht, 2006, S. 769.

68 Vgl. dazu Europäischer Gerichtshof: Urteil vom 06.07.1982, verb. Rs. 188-190/80, Frankreich, Italien und Vereinigtes Königreich gegen Kommission, Slg. 1982, 2545, 1. Leitsatz; Europäischer Gerichtshof: Urteil vom 17.11.1992, verb. Rs. C-271/90, C-281/90 und C-289/90, Spanien, Belgien u. Italien gegen Kommission, Slg. 1992, I-5833, Rdnr. 12. Danach erlaubt Art. 86 Abs. 3 EGV „der Kommission den Erlass von Richtlinien und räumt ihr damit die Befugnis ein, allgemeine Regeln zu erlassen, durch die die sich aus dem Vertrag ergebenden Verpflichtungen konkretisiert werden und die für die Mitgliedstaaten hinsichtlich der in den Absätzen 1 und 2 dieses Artikels genannten Unternehmen gelten." $\mathrm{Zu}$ den Normsetzungsbefugnissen der Kommission in der allgemeinen Normenhierarchie des Unionsrechts siehe Ulrich Wölker: Die Normenhierarchie im Unionsrecht in der Praxis, in Europarecht 1/2007, S. 32-56, hier S. 35. 
19.1, Art. 22 und Art. 25.2 ESZB-Satzung ${ }^{69}$ ) erlassenen EZB-Verordnungen ${ }^{70}$ haben, da nur ersteres, nicht aber letztere nach dem Vertrag von Lissabon Gesetzescharakter haben werden. ${ }^{71}$

Auch bei Entscheidungen über den EU-Haushalt stärkt der Lissabon-Vertrag die Demokratie. Während die Höhe der Einnahmen der Union auch in Zukunft von den Mitgliedstaaten und damit von den nationalen Parlamenten kontrolliert wird, ${ }^{72}$ entscheidet das Europäische Parlament künftig über alle Ausgaben gleichberechtigt mit dem EU-Ministerrat. ${ }^{73}$ Im Lissabon-Vertrag erfolgt ferner eine weitgehende Parlamentarisierung der EU-Außenbeziehungen, da er die große Mehrheit der internationalen Übereinkünfte der Europäischen Union von der Zustimmung des Europäischen Parlaments abhängig macht. ${ }^{74}$ Zudem wird die Gemeinsame Außenund Sicherheitspolitik künftig von einem „Hohen Vertreter der Union für Außen- und Sicherheitspolitik “ geleitet, ${ }^{75}$ der zugleich Vizepräsident der Europäischen Kommission ist ${ }^{76}$ und sich als solcher wie alle anderen Kommissare vor dem Europäischen Parlament zu verantworten hat.

Bemerkenswert ist schließlich die neu gestaltete Wahl des Präsidenten der Europäischen Kommission. Dieser wird nach der Reform von Lissabon durch das Europäische Parlament mit der Mehrheit seiner Mitglieder auf Vorschlag des mit qualifizierter Mehrheit beschließenden Europäischen Rates (also der Staats- oder Regierungschefs der 27 Mitgliedstaaten ${ }^{77}$ ) gewählt, wobei der Europäische Rat bei seinem Personalvorschlag ,das Ergebnis der Wahlen zum Europäischen Parlament" zu berücksichtigen und zuvor Konsultationen mit den politischen Fraktionen im Europäischen Parlament durchzuführen hat (Art. 17 Abs. 7 EUV ${ }^{78}$ ). Dadurch rückt die Stellung des Kommissionspräsidenten ein ganzes Stück mehr in die Richtung des Regierungschefs einer parlamentarischen Demokratie. Mittelfristig könnte dies dazu führen, dass Parteien europaweit mit jeweils einem Spitzenkandidaten bei den Europawahlen antreten, der im Fall eines Wahlsiegs Kommissionspräsident werden soll. Die Zeiten, in denen die Kommission als unpersönliche, technokratische und bürgerferne Behörde verstanden wurde, wären damit endgültig vorbei.

69 Vgl. Protokoll über die Satzung des Europäischen Systems der Zentralbanken und der Europäischen Zentralbank, in: Amtsblatt der Europäischen Gemeinschaften, Nr. C 191 vom 29. Juli 1992, S. 68-79; inoffizielle konsolidierte Fassung des Protokolls über die Satzung des Europäischen Systems der Zentralbanken und der Europäischen Zentralbank, abrufbar unter: http://www.ecb.int/ecb/legal/pdf/de_statute.pdf (letzter Zugriff: 10.07.2008)

70 Zu EZB-Verordnungen siehe Zilioli/Selmayr: The Law of the European Central Bank, 2001, S. 91-94.

$71 \mathrm{Zu}$ einem solchen möglichen Konfliktfall bei den Rechtsvorschriften zur Gestaltung der Euro-Banknoten siehe Chiara Zilioli/Martin Selmayr: The constitutional status of the European Central Bank, in: Common Market Law Revue 2/2007, S. 355-399, hier S. 378-381, 395-396. Zu einem realen Konflikt bei der Ausgestaltung von Betrugsbekämpfungsregeln siehe Europäischer Gerichtshof: Urteil vom 10.07.2003, Rs. C-11/00, Kommission gegen Europäische Investitionsbank, Slg. 2003, I-7147, Rdnr. 134-135.

72 Art. 311 Abs. 3 AEUV.

73 Art. 314 AEUV. Die bisherige, im Einzelnen ohnehin regelmäßig umstrittene Unterscheidung zwischen obligatorischen und nichtobligatorischen Ausgaben, entfällt ersatzlos.

74 Art. 218 Abs. 6 UAbs. 2 Buchstabe a AEUV. Erreicht wird dies unter anderem dadurch, dass Art. 218 Abs. 6 UAbs. 2 Buchstabe a Ziff. v AEUV die parlamentarische Zustimmung zu einem völkerrechtlichen Vertrag der Union immer dann verlangt, wenn dieser einen Bereich betrifft, für den beim Erlass interner Bestimmungen entweder das ordentliche Gesetzgebungsverfahren gilt oder im Rahmen eines besonderen Gesetzgebungsverfahrens die Zustimmung des Europäischen Parlaments erforderlich ist. Dies erfasst in der Praxis gut 95 Prozent aller möglichen internationalen Übereinkünfte, für welche die Union eine Vertragsschlusskompetenz hat. Zudem unterliegt in Zukunft der Erlass wichtiger handelspolitischer Instrumente - so insbesondere AntidumpingVerordnungen - gemäß Art. 207 Abs. 2 AEUV dem ordentlichen Gesetzgebungsverfahren.

75 Art. 18 Abs. 2 Satz 1 EUV.

76 Art. 18 Abs. 4 EUV.

77 Art. 17 Abs. 7 i.V.m. Art. 15 Abs. 2 EUV und Art. 235 Abs. 1 UAbs. 2 AEUV.

78 Vgl. Erklärung Nr. 11 zum Vertrag von Lissabon: Erklärung zu Artikel 9d Absätze 6 und 7 des Vertrags über die Europäische Union, in: Amtsblatt der Europäischen Union, Nr. C 306 vom 17. Dezember 2007, S. 254. 


\section{Der Lissabon-Vertrag als Ergebnis der parlamentsfreundlichen Konventsmethode}

Der neue Vertrag ist insgesamt also keineswegs, wie in den nun eingereichten Verfassungsbeschwerden unterstellt, eine ,Gefahr für die Demokratie", sondern verdient aufgrund seiner zahlreichen parlamentsfreundlichen Innovationen den Beinamen ,Vertrag der Parlamente'. Dies liegt nicht zuletzt daran, dass sein Inhalt - im Unterschied zu all seinen Vorgängerverträgen - nicht vorwiegend von Diplomaten auf einer Regierungskonferenz ausgehandelt wurde, sondern weitgehend auf die Vorarbeit eines von Parlamentariern dominierten Konvents zurückgeht. ${ }^{79}$ Mit der Einberufung eines solchen Konvents hatte die Europäische Union bereits bei der Erarbeitung der Grundrechte-Charta durch den Grundrechte-Konvent, der 1998/1999 unter Vorsitz des früheren Bundespräsidenten Roman Herzog tagte, gute Erfahrungen gemacht. Auch die Reform der Europäischen Union, die jetzt Inhalt des LissabonVertrags wird, ist von einem solchen Konvent 2002/2003 öffentlich beraten worden. Die Mitglieder dieses Konvents waren zu mehr als zwei Dritteln (72 von 105) Abgeordnete aus nationalen Parlamenten (56) und aus dem Europäischen Parlament (16), die damit ein deutliches Übergewicht gegenüber den Konventsvertretern der nationalen Exekutiven hatten. Viele Fortschritte konnten im Konvent dadurch erreicht werden, dass nationale Parlamentarier und Europaabgeordnete eine konstruktive ,Allianz der Parlamentarier' eingingen. Stand bei bisherigen europäischen Verträgen die Mitwirkung nationaler Parlamente unter der Devise ,Friss, Vogel, oder stirb', da die Abgeordneten nur die Wahl zwischen Annahme oder Ablehnung des Vertrags hatten, ${ }^{80}$ ermöglichte es die der Entstehung des Lissabon-Vertrags vorgeschaltete Konventsmethode erstmals, dass nationale und Europaparlamentarier den neuen Vertragstext von Anfang an selbst durch eigene Vorschläge und Formulierungen aktiv mitgestalteten. So kann der CDU-Bundestagsabgeordnete Peter Altmaier, der sowohl Mitglied des Grundrechte-Konvents als auch des Verfassungskonvents war, seine Handschrift im neuen Vertrag deutlich an der Festschreibung der Rechtsverbindlichkeit der „Charta der Grundrechte der Europäischen Union“81 in Art. 6 Abs. 1 EUV erkennen, womit einer bereits 1974 vom BVerfG erhobenen Forderung nach einem in Geltung stehenden kodifizierten europäischen Grundrechte-Katalog ${ }^{82}$ Rechnung getragen wird. Auf das Verhandlungsgeschick des damaligen SPD-Bundestagsabgeordneten Jürgen Meyer im Konvent ist es zurückzuführen, dass mit der Unionsbürgerinitiative nun in Art. 11 Abs. 4 EUV erstmals

79 Zur ,Konventsmethode' aus Sicht der Teilnehmer Elmar Brok/Martin Selmayr: EU-Verfassungskonvent und Regierungskonferenz: Monnet oder Metternich?, in: Werner Weidenfeld (Hrsg.): Die Europäische Union. Politisches System und Politikbereiche, Bonn 2004, S. 673-693; Thomas Oppermann: Vom Nizza-Vertrag 2001 zum Europäischen Verfassungskonvent 2002/2003, in: Deutsches Verwaltungsblatt 1/2003, S. 1-9; Thomas Oppermann: Europäischer Verfassungskonvent, 2004, S. 1264; Alain Lamassoure: Histoire secrète de la Convention européenne, Paris 2004; Alain Dauvergne: L'Europe en otage? Histoire secrète de la Convention, Paris 2004; Andreas Wehr: Europa ohne Demokratie?, Köln 2004; Peter Norman: The Accidental Constitution. The Story of the European Convention, Brüssel 2003. Aus Sicht der Wissenschaft Stefan Hobe: Bedingungen, Verfahren und Chancen europäischer Verfassungsgebung: Zur Arbeit des Brüsseler Verfassungskonvents, in: Europarecht 1/2003, S. 1-16; Daniel Göler/Mathias Jopp: Der Konvent und die Europäische Verfassung, in: Werner Weidenfeld/Wolfgang Wessels (Hrsg.): Jahrbuch der Europäischen Integration 2002/2003, Bonn 2003, S. 35-46; Andreas Maurer/Daniel Göler: Die Konventsmethode in der Europäischen Union. Ausnahme oder Modell?, SWP-Studie S 44, Berlin 2004; Oliver Beaud/Arnauld Lechevalier/Ingolf Pernice/Sylvie Strudel (Hrsg.): L'Europe en voie de Constitution. Pour un bilan critique des travaux de la Convention, Brüssel 2004.

80 Vgl. § 82 Abs. 2 der Geschäftsordnung des Deutschen Bundestages: „Zu Verträgen mit auswärtigen Staaten und ähnlichen Verträgen, welche die politischen Beziehungen des Bundes regeln oder sich auf Gegenstände der Bundesgesetzgebung beziehen (Artikel 59 Abs. 2 des Grundgesetzes), sind Änderungsanträge nicht zulässig."

81 Vgl. Charta der Grundrechte der Europäischen Union, in: Amtsblatt der Europäischen Union, Nr. C 303 vom 14. Dezember 2007, S. 1-16.

82 BVerfGE 37, $271(280,285)$ 
ein Element der direkten Demokratie im Unionsrecht verankert wird. Einen sichtbaren Widerhall im Vertrag von Lissabon findet auch das Engagement des damaligen Europaabgeordneten Joachim Wuermeling, der im Konvent gemeinsam mit dem damaligen Ministerpräsidenten Baden-Württembergs Erwin Teufel dafür sorgte, dass die Union künftig ausdrücklich zur Achtung der ,regionalen und lokalen Selbstverwaltung“ verpflichtet ist (Art. 4 Abs. 2 Satz 1 EUV). Auf die Arbeit der vom früheren SPD-Europaabgeordneten Klaus Hänsch geleiteten Konvents-Arbeitsgruppe „Ordnungspolitik“ gehen die verfahrensrechtlichen Verbesserungen des ,Stabilitätspakts“ (Warnschreiben künftig direkt von der Kommission ${ }^{83}$ ) zurück. Und auch Sylvia-Yvonne Kaufmann, die als Europaabgeordnete für die Linkspartei an der Konventsarbeit sehr aktiv teilnahm, unterstützte erfolgreich die Verankerung sozialer Ziele wie ,Vollbeschäftigung“ und ,soziale Gerechtigkeit“" im neuen Vertrag (Art. 3 Abs. 3 EUV). Die insgesamt positiven Erfahrungen mit der parlamentsfreundlichen Konventsmethode erklären, warum der Vertrag von Lissabon vorsieht, dass auch in Zukunft alle grundlegenden Vertragsreformen von einem solchen Konvent vorbereitet werden sollen (Art. 48 Abs. 3 EUV).

\section{Schlussfolgerung: Politische Argumente gehören vor den Bundestag, nicht nach Karlsruhe}

Das BVerfG hat im letzten Satz seines Maastricht-Urteils 1993 folgende Erwartung an die Entwicklung der Demokratie in der Europäischen Union ausgesprochen: „Entscheidend ist [...] sowohl aus vertraglicher wie aus verfassungsrechtlicher Sicht, dass die demokratischen Grundlagen der Union schritthaltend mit der Integration ausgebaut werden und auch im Fortgang der Integration in den Mitgliedstaaten eine lebendige Demokratie erhalten bleibt. " 84 Genau dieser Erwartungshaltung trägt jetzt der neue Vertrag Rechnung. Auch wenn sich in der Reform von Lissabon nicht alle politischen Wunschträume verwirklichen, erfüllt der ,Vertrag der Parlamente' doch Demokratie und Parlamentarismus in Europa mit neuem Leben und eröffnet so den Weg in eine demokratischere und bürgernähere Union. Die Verfassungsklagen gegen den Vertrag von Lissabon sind vor diesem Hintergrund - sofern sie überhaupt als zulässig angesehen werden können - jedenfalls unbegründet.

Nur prozedural ist zu erklären, dass sich Gauweiler und die Linksfraktion in ihren Klagen dennoch auf eine Verletzung des Art. 38 Abs. 1 Satz 2 GG stützen und damit auf eine Vorschrift, die genau die Rechte des Bundestages in der Europäischen Union wahren soll, welche durch den neuen Vertrag ausgebaut und gestärkt werden. Die angebliche Verletzung der Parlamentsrechte wird von den Beschwerdeführern offensichtlich nur als Hebel benutzt, um ihren politischen Bedenken gegen das Vertragswerk insgesamt Ausdruck zu verleihen. So verwendet Gauweiler seinen 342-seitigen Schriftsatz dazu, um in der Sache darzulegen, dass der neue Vertrag die Europäische Union zu einem (von ihm abgelehnten) Bundesstaat mache, der stabile Euro und die Rechtsprechung des Europäische Gerichtshofs das ,Sozialprinzip" des Grundgesetzes verletzten und die Grundrechte-Charta die Einführung der Todesstrafe (!) ermögliche - alles Argumente aus dem euroskeptischen Nähkästchen, die im Lissabon-Vertrag nicht den geringsten juristischen Anhaltspunkt finden. Ähnlich sieht die Linksfraktion in ihrer Klage eine Gelegenheit, um gegen das aus ihrer Sicht ,neoliberale“ und ,militaristische" Europa zu wettern - was rechtlich gesehen angesichts des ausdrücklichen Bekenntnisses des Lissabon-Vertrags zur „,sozialen Marktwirtschaft“ (Art. 3 Abs. 3 EUV), zum „Frieden“ und „zur strikten Einhaltung und Weiterentwicklung des Völker-

83 Art. 121 Abs. 4 UAbs. 1 Satz 1 AEUV.

84 BVerfGE 89, 155 (213). 
rechts" (Art. 3 Abs. 5 EUV) mehr als an den Haaren herbeigezogen ist. Zwar handelt es sich dabei ohne Zweifel um im politischen Meinungskampf legitime politische Argumente gegen den Vertrag von Lissabon. Diese gehören allerdings nicht nach Karlsruhe, sondern in die demokratische Auseinandersetzung vor den Bundestag, der seine Entscheidung nach eingehender Debatte am 24. April 2008 mit 515 Ja-Stimmen bei 58 Nein-Stimmen und einer Enthaltung getroffen hat. Verfassungsrechtlich verdienen diese Sachargumente allesamt das Verdikt „offensichtlich unbegründet“ ( $\$ 24$ BVerfGG).

Gauweiler berühmt sich bis heute, mit seiner Klage gegen den Verfassungsvertrag diesen in Deutschland zum Scheitern gebracht zu haben ${ }^{85}$ - eine äußerst vermessene Gleichsetzung seiner juristischen Schriftsätze mit den Voten der französischen und niederländischen Bevölkerung, die erneut deutlich macht, dass es ihm in Wirklichkeit nicht um die Wahrung der repräsentativ-demokratischen Rechte des Bundestages geht, sondern um die Durchsetzung seiner in der parlamentarischen Auseinandersetzung unterlegenen Mindermeinung. Auch das in den Verfassungsklagen der Linksfraktion vorgebrachte Argument, durch den Vertrag von Lissabon werde das BVerfG „entmachtet“, dient offenbar vor allem dazu, das BVerfG zu einer Sachentscheidung aus eigenem Interesse zu motivieren. Welches Gericht, so denken sich wohl die listigen Kläger, wird schon seiner ,Selbstentmachtung ' zustimmen? Dass der Vertrag von Lissabon zahlreiche langjährige Forderungen des BVerfG (GrundrechteCharta, Stärkung der nationalen Parlamente, Einbeziehung der polizeilichen und justiziellen Zusammenarbeit in die rechtsstaatliche Kontrolle durch nationale Gerichte und Europäischen Gerichtshof ${ }^{86}$ ) direkt aufgreift und damit dem europäischen Primärrecht geradezu den machtvollen Karlsruher Stempel aufdrückt, wird dabei geflissentlich übersehen.

Es ist zu hoffen, dass das BVerfG vor diesem Hintergrund und in Respekt vor der Entscheidung von Bundestag und Bundesrat mit der Abweisung der Verfassungsklagen gegen das Zustimmungsgesetz zum Vertrag von Lissabon nicht lange zögern wird. Auch wenn für manch einen Verfassungsrichter die Versuchung groß sein mag, die jetzt anhängigen Klagen dafür zu nutzen, um der Europäischen Union in einer ,Solange III'-Entscheidung noch rasch den einen oder anderen verfassungsrechtlichen Grundsatz ins Stammbuch zu schreiben: Dies ist dafür der falsche Zeitpunkt. Wenn man die seit Jahren gerade von Deutschland befürwortete politische Reform der Europäischen Union und die vom BVerfG immer wieder eingeforderten parlamentarischen und rechtsstaatlichen Verbesserungen des europäischen Entscheidungsprozesses trotz des negativen Ausgangs des irischen Referendums doch noch zu einem erfolgreichen Abschluss bringen will, dann muss die deutsche Europapolitik in den kommenden Monaten mehr denn je handlungsfähig sein. Dann sollte das Verfassungsge-

85 Vgl. hierzu Peter Gauweiler: Bundesverfassungsgericht: Keine Ratifizierung der EU-Verfassung in absehbarer Zeit. EU-Verfassung aller Voraussicht nach auch in Deutschland gescheitert, Pressemitteilung, 31.10.2008, abrufbar unter: http://www.peter-gauweiler.de/pdf/PresseerklaerungEUVerfassung31.10.06.pdf (letzter Zugriff: 09.07.2008); Karl Albrecht Schachtschneider: Der Vertrag von Lissabon, S. 1, abrufbar unter: http://www.kaschachtschneider.de/Schriften/Dokumente-herunterladen/Pelagius1.pdf (letzter Zugriff: 09.07.2008): „Nachdem der Vertrag über eine Verfassung für Europa von 2004, der Verfassungsvertrag, in Frankreich und in den Niederlanden durch Volksabstimmungen und in Deutschland wegen der von mir vertretenen Verfassungsbeschwerde des Bundestagsabgeordneten Dr. Peter Gauweiler gescheitert ist.“

86 Nach der bisher geltenden Rechtslage (Nizza-Vertrag) ist die gerichtliche Kontrolle der sogenannten ,Dritten Säule ' der EU mehrfach beschränkt: Natürliche und juristische Personen können keine Individualklagen gegen in der ,Dritten Säule' gefasste Rahmenbeschlüsse und Beschlüsse erheben; nationale Gerichte sind in ihrem Recht, Vorabentscheidungsersuchen an den Europäischen Gerichtshof zu richten, begrenzt; und die Kommission hat nicht die Möglichkeit, einen Mitgliedstaat wegen vertragswidrigen Verhaltens vor dem Europäischen Gerichtshof zu verklagen. Vgl. Art. 35 EUV-Nizza. Der Vertrag von Lissabon ändert dies, indem er diese Begrenzungen ersatzlos streicht und die bisherige ,Dritte Säule' in das Rechtsschutzsystem der Union (das nationale Gerichte und den Europäischen Gerichtshof umfasst) einbezieht. Vgl. den insofern ausnahmslos formulierten Art. 19 Abs. 1 UAbs. 1 Satz 2 EUV. 
richt dem Bundespräsidenten und der Bundesregierung ermöglichen, den Vertrag von Lissabon so schnell wie möglich zu ratifizieren, so wie es Bundestag und Bundesrat beschlossen haben. Nur wenn 26 der 27 Mitgliedstaaten den Vertrag von Lissabon ratifizieren, kann Irland vielleicht noch dazu bewegt werden, einen zweiten Ratifizierungsanlauf zu wagen. Andernfalls fiele die Europäische Union zurück auf die unzureichende Vertragsgrundlage von Nizza. Und das ließe für die Zukunft eines demokratischen, bürgernäheren und rechtsstaatlicheren Europas wenig Gutes erwarten.

\section{Südosteuropa aktuell}

Vergleich der EU-Tauglichkeit von Kroatien und BosnienHerzegowina

Von Franziska Pommer

2008, 226 S., brosch., 44,-€,

ISBN 978-3-8329-3644-O

\section{Sicherheitspolitik} im Südkaukasus

Zwischen balancing, Demokratisierung und zögerlicher Regimebildung Von Franz Eder

2008, 252 S., brosch., 46,- $€$, ISBN 978-3-8329-3581-8

(Nomos Universitätsschriften - Politik, Bd. 155)

\author{
Slowenien - Ein Grenzland \\ mit Vorbildfunktion \\ Von Andreas Veres \\ 2008, 323 S., brosch., 69,-€, \\ ISBN 978-3-8329-3645-7 \\ (Demokratie, Sicherheit, Frieden, \\ Bd. 190)
}

\section{Konfliktbeilegung durch Europäisierung?} Zypernfrage, Ägäis-Konflikt und griechisch-mazedonischer Namensstreit

Von Heinz-Jürgen Axt, Oliver Schwarz und Simon Wiegand 2008, 285 S., brosch., 39,- $€$, ISBN 978-3-8329-3606-8 